\title{
Analysis Of The Influence Of Temperature Field On Hulll Local Strength
}

\author{
Zhenxiao Shi, Yifeng Guan
}

\begin{abstract}
Because the asphalt is kept at $180 \mathrm{C}$ during transportation, the asphalt temperature has an effect on the structural stress of the ship hull. This paper mainly discusses the effect of temperature on the local structural strength of the asphalt ship. Taking an asphalt ship as an example, the whole cargo tank area is modeled by using finite element software MSC. Patran and MSC. Nastran. The model is established by referring to the relevant provisions in the Code for Construction of Steel Inland River Ships. The finite element mesh of the model is generated by choosing the appropriate element type. Applying temperature boundary conditions, the calculated temperature field is applied to the model in the form of load, and other boundary conditions are applied to establish a variety of working conditions, calculate the structural strength, and obtain the stress distribution of the hull. Considering the thermal stress with or without temperature, the effect of temperature on hull structure is analyzed.
\end{abstract}

\section{Index Terms - Asphalt ship Temperature Intensity}

\section{INTRODUCTION}

Temperature stress is a very important problem in ship, civil engineering, hydraulic engineering and mechanical engineering. With the improvement of structure reliability, safety and durability requirements, temperature stress by the researchers and engineers from all walks of life more and more attention, especially for mass structure and structure under high temperature gradient, temperature stress and sometimes play a decisive role for the safety and durability of engineering structure ${ }^{[1] \sim[3]}$.

Many structural stress analysis problems involve both mechanical load and thermal load. When elastic structureWhen there is a temperature change in the body, the internal material will generate heat through heat transfer to establish the corresponding temperature field.

Most elastic materials tend to expand or contract as their volume changes with temperature. However, due to the external constraints on the elastomer and the mutual constraints between the parts, this expansion or contraction can not occur freely, resulting in internal stress, namely temperature stress. When the temperature change is large enough, the thermal stress can reach a level that leads to structural failure, especially for brittle materials. In some structures, the temperature stress is often more than the stress produced by conventional load as the main control factor, and easy to cause fatigue and cracking of the structure, endangering the safety of the structure. Therefore, it is necessary to analyze the special temperature stress of engineering structures that need to undergo large temperature changes ${ }^{[4] \sim[6]}$. As for the hull structure, the calculation of its

Zhenxiao Shi, Yifeng Guan, School of Naval Architecture \& Ocean Engineering , Jiangsu University of Science and Technology, Zhenjiang, Jiangsu, China temperature stress mainly involves the temperature stress of the beam, plate and shell structure ${ }^{[7]}$.

\section{ESTABLISH FINITE ELEMENT MODEL}

\section{A Ship type description}

Take a 3500t class asphalt ship as an example, sailing in A, B, C, J2 class and three gorges reservoir area. The ship's main dimensions and main parameters are as follows:

Table1.1 Main parameters of the target ship

\begin{tabular}{llll}
\hline Main scale & $\begin{array}{l}\text { symb } \\
\text { ol }\end{array}$ & $\begin{array}{l}\text { Numeri } \\
\text { cal } \\
\text { value }\end{array}$ & Unit \\
\hline The total length & $L_{O A}$ & 103 & $\mathrm{~m}$ \\
Water line length & $L_{W L}$ & 101 & $\mathrm{~m}$ \\
Type of wide & $B$ & 16.2 & $\mathrm{~m}$ \\
Deep & $D$ & 5.3 & $\mathrm{~m}$ \\
The design draft & $d$ & 4.3 & $\mathrm{~kg}$ \\
\hline
\end{tabular}

Asphalt ship adopts integral cargo tank, which is similar to tanker structure. The cargo compartment is double-shell and double-bottom structure, with $600 \mathrm{~mm}$ frame spacing, $600 \mathrm{~mm}$ longitudinal bone spacing, $850 \mathrm{~mm}$ double-bottom height and $1800 \mathrm{~mm}$ strong frame spacing. There are 6 double bottom longitudinal girders and 5 upper deck longitudinal girders; Cargo oil tank area (Fr66 Fr116), from tank middle longitudinal bulkhead, tank transverse bulkhead (Fr78, Fr103 respectively). The heat insulation material of liquid cargo tank of asphalt ship is rigid polyurethane foam material. In addition, thermal insulation materials of $150 \mathrm{~mm}$ thick are laid on the inner shell plate, inner bottom plate, deck and the front and last two plane transverse bulkheads in the cargo oil tank area, and thermal insulation materials are laid on the upper end, lower end and side of the channel longitudinal bulkhead and channel transverse bulkhead.

\section{B Establishment of hull section model}

It is due to the vertical and horizontal tank in the cargo tank wall is not a heat insulation material, contact directly with high temperature in the middle of the asphalt, the section temperature is $180^{\circ} \mathrm{C}$, the entire model take " $1 / 2+1+1 / 2$ " segment of the finite element analysis model.In the coordinate system of the model,the right-handed rectangular coordinate system is adopted: the origin of the coordinate is located at the ship's centerline Fr66, and the $\mathrm{X}$-axis is in the longitudinal direction of the ship, with the heading positive; The Y-axis is in the direction of ship width, and the port side is positive; $\mathrm{Z}$ axis along the height direction, up is positive.According to the 
provisions ${ }^{[8]}$, the finite element grid in this model is divided along the ship's hull horizontally according to the longitudinal spacing, and longitudinally according to the rib spacing. The outer plate structure, grooved bulkhead, strong frame, longitudinal girder, rib and other high webs of the hull are simulated by 4 -node plate grid elements. Triangular elements are used as little as possible in the high-stress area and high-stress change area. Meanwhile, some triangular elements are used in some transition and connection points. Most of the panels on the longitudinal, truss and bracket adopt beam element to simulate, but few adopt plate element. The thermal insulation materials of cargo oil tank are all body units, the vast majority of body units are hexahedral units, a small number of wedge-shaped units (pentahedral) and a very small number of tetrahedral units are adopted at the connection, and the units can be simplified according to the actual situation at the intersection of longitudinal and transverse tank bulkheads. In the model, the grooved steel plates fixed to the thermal insulation materials are not considered.

Ordinary steel: elastic modulus E=2.06 105MPa, poisson's ratio 0.3 , density $7.85 \mathrm{t} / \mathrm{m} 3$, yield strength 235 $\mathrm{N} / \mathrm{mm} 2$. The thermal conductivity of carbon steel is -- for heat transfer analysis (temperature analysis). The linear expansion coefficient of carbon steel is -- for thermal stress analysis (structural analysis). The heat transfer coefficient of the heat insulation material hard polyurethane foam material is. The finite element model is shown in figure 1 and figure 2 below.

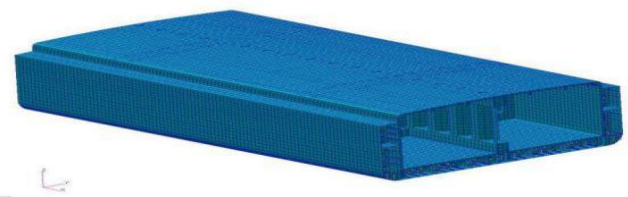

Fig 1 Temperature field calculation finite element model.

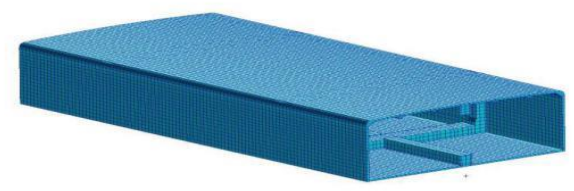

Fig 2 Temperature field calculation local finite element model(internal heat insulation material)

\section{THE BOUNDARY CONDITIONS}

\section{A Thermal stress boundry conditions}

In the calculation, it is assumed that heat transfer is carried out among the hull members in the way of heat conduction, and air convection is only carried out between the hull members in contact with air in the way of natural convection, without considering the heat conduction of air or the heat radiation of structural members.Its boundary conditions are as follows:(1) of shell plate below the waterline in contact with the water surface temperature of the definition of sailing for the lowest water temperature, take $0{ }^{\circ} \mathrm{C}$; (2) in the atmosphere above the waterline and environment components in contact with the surface temperature of the definition of the atmospheric environment in navigation may reach the lowest temperature, take - $20{ }^{\circ} \mathrm{C}$; (3) the cargo tank insulation material surface and the longitudinal and transverse bulkhead direct contact with the surface of the part of the definition of cargo oil temperature for liquid cargo (asphalt) when carrying up to the highest temperature stability, take $180^{\circ} \mathrm{C}$.

\section{1) B Boundary conditions of structural model}

The ship floats on the surface of the water and is in a state of stress balance. In finite element analysis to the rigid motion of the structure under restrictions, in order to calculate the relative deformation of the structure, so must give hull model with appropriate constraints, restrictions on the hull of the rigid motion and, guarantee the freedom of hull deformation, in order to reflect the stress of the structure, in this way can find out the relative deformation and internal force of the real fitting the actual situation.In the study of this paper, considering the hold by the synthetic load make integral structure makes the longitudinal bending, there is no torque load, according to the steel construction rules inland river ships (2016), chapter 1 "general principles of the" 9 "structural strength directly computing" $1.9 .5 \quad 1.9 .5 .8$ requirements in "total longitudinal bending strength", for the midship tank finite element model, boundary conditions are as follows:(1) the model is close to the stern plane, i.e., the vertical section at Fr66. An independent point is established in this section and on the axis.(2) the model is close to the bow plane, that is, the vertical section at Fr116. An independent point is established in this section and on the axis. Other nodes on the end face are associated with independent points, and bending moment is applied at independent points, that is, MPC2 is established. As shown in figure 3.

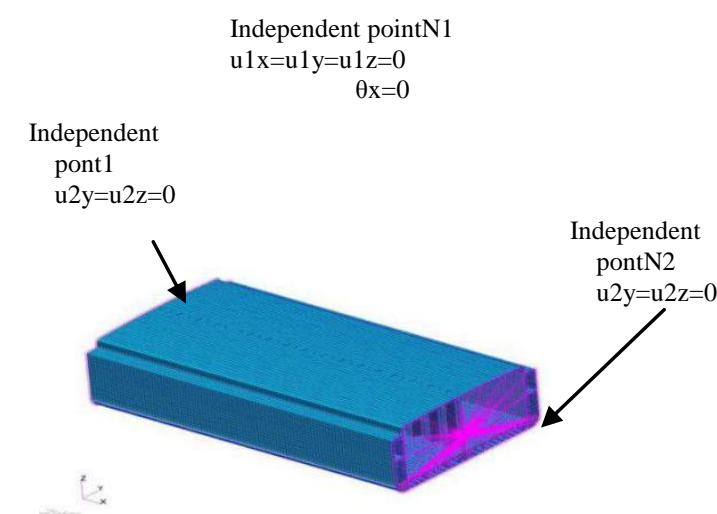

Fig 3 Model constraint diagram

\section{CALCULATE WORKING CONDITIONS AND LOADS}

\section{A Working conditions}

For the actual sailing conditions, the weight distribution data of two load conditions (full load sailing and half load sailing) were referred to. The combination of two load conditions and two wave breaking conditions gives four calculation conditions, as shown in table 1

Table 1 Calculation condition description

\begin{tabular}{cll}
\hline Conditions & Description & Bending \\
\hline LC1 & $\begin{array}{l}\text { Sailing conditionsDraft full } \\
\text { load +Half wave high) }\end{array}$ & hogged \\
LC2 & $\begin{array}{l}\text { Sailing conditionsHalf } \\
\text { draftHalf wave high) }\end{array}$ & sagging \\
& $\begin{array}{l}\text { Sailing conditionsDraft full } \\
\text { load +Half wave high) }\end{array}$ & hogged \\
LC3 & $\begin{array}{l}\text { Sailing conditionsHalf } \\
\text { draftHalf wave high) }\end{array}$ & sagging \\
\hline
\end{tabular}




\section{$B$ Computational load}

Outboard water pressure equation

Pstatic $=9810 \times(\mathrm{d}+\mathrm{R}-\mathrm{Z})$

d -- draft calculated at full load;

$\mathrm{R}$-- the half-wave height corresponding to the navigation area;

' $\mathrm{Z}$ - calculate the height from the point to the baseline.

Hold cargo pressure:

The liquid pressure on the side, inboard and bulkhead with liquid cargo on only one side shall be calculated according to the following three equations, whichever is the largest:

$p=\max \begin{cases}\rho a_{v} z & k N / m^{2} \\ \rho a_{t} y & k N / m^{2} \\ \rho a_{L} x & k N / m^{2}\end{cases}$

$\rho$-- mass density of liquid goods;

\section{CALCULATE WORKING CONDITIONS AND LOADS}

\section{A Temperature field calculation results}

The temperature field of the model was calculated by using MSC.Nastran thermal analysis, and the maximum and minimum values of the temperature stress on each structure of the model were obtained as shown in table 2 and table 3 .

Table2 The calculation results of the maximum and minimum temperature of each component.

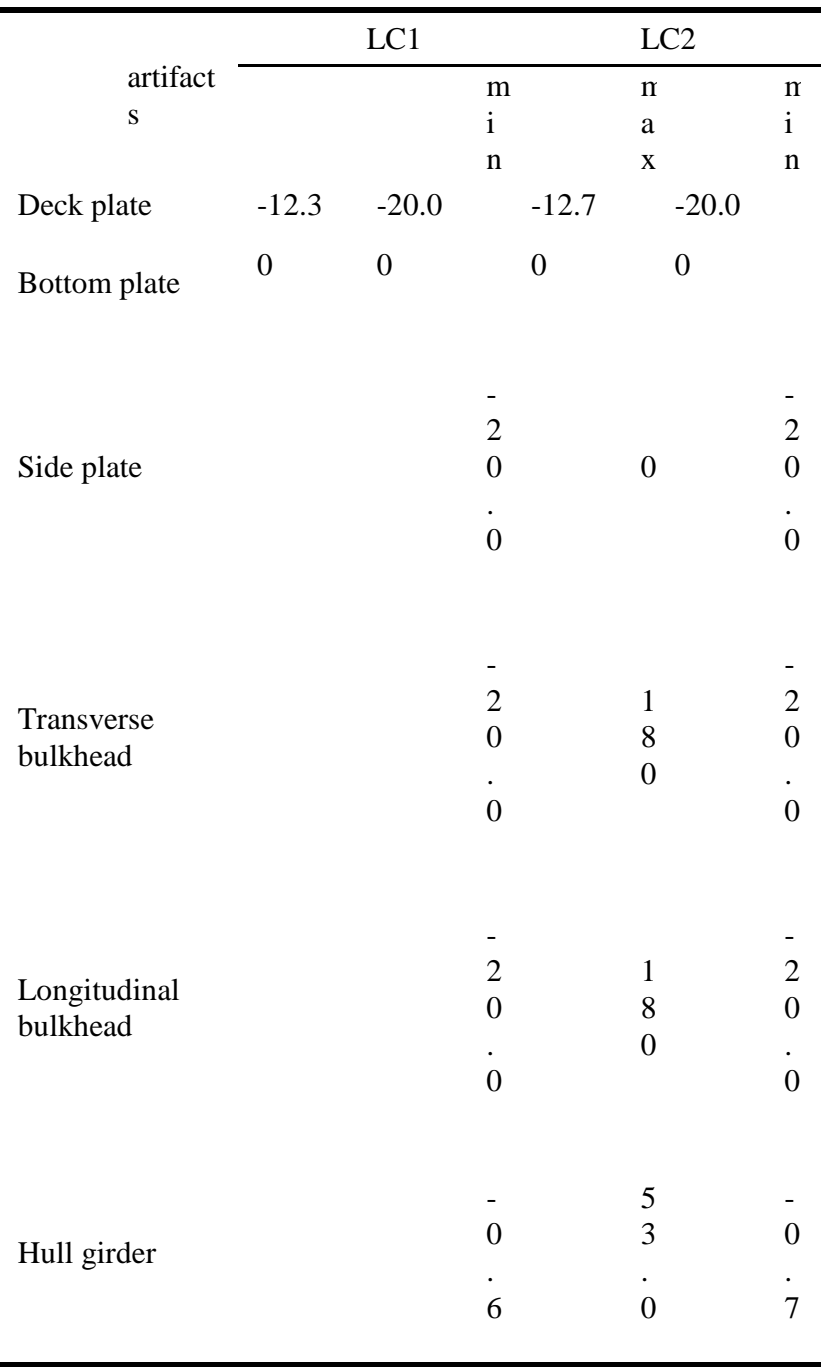

Table3 The calculation results of the maximum and minimum temperature of each component.

\begin{tabular}{|c|c|c|c|c|c|}
\hline \multirow{4}{*}{$\begin{array}{l}\text { artifac } \\
\text { ts }\end{array}$} & \multicolumn{3}{|c|}{ LC3 } & \multicolumn{2}{|l|}{ LC4 } \\
\hline & & & $\mathrm{m}$ & $\mathrm{n}$ & $\mathrm{n}$ \\
\hline & & & i & a & i \\
\hline & & & $\mathrm{n}$ & $\mathrm{x}$ & $\mathrm{n}$ \\
\hline Deck plate & -12.3 & -20.0 & -12.7 & -20.0 & \\
\hline Bottom plate & 0 & 0 & 0 & 0 & \\
\hline & & & - & 0 & - \\
\hline & & & 2 & & 2 \\
\hline Side plate & & & 0 & & 0 \\
\hline & & & 0 & & 0 \\
\hline & & & - & & - \\
\hline & & & 2 & 1 & 2 \\
\hline hulkbead & & & 0 & 8 & 0 \\
\hline & & & . & 0 & . \\
\hline & & & 0 & & 0 \\
\hline & & & - & & - \\
\hline Longitudinal & & & 2 & 1 & 2 \\
\hline bulkhead & & & 0 & 8 & 0 \\
\hline & & & . & 0 & - \\
\hline & & & 0 & & 0 \\
\hline & & & & 5 & 0 \\
\hline Hull girder & & & 0 & 4 & \\
\hline & & & & 5 & \\
\hline
\end{tabular}

It can be seen from the above:

(1) The temperature transfer at the structural joints is obvious and linear, while the temperature at the connection between the grooved bulkhead and the strong members is low.

(2) The components in contact with the surrounding medium (air and water), such as the deck, bottom plate and side shell plate, have stable temperature, which is basically consistent with the external temperature and less affected by the temperature of goods.

(3) Except for the part in contact with the transverse bulkhead, the temperature of other members varies greatly in the transverse direction and little in the longitudinal direction.

1) B Temperature stress calculation results In the finite element calculation process, other external forces applied with temperature load and boundary conditions unchanged are shown in the figure 4

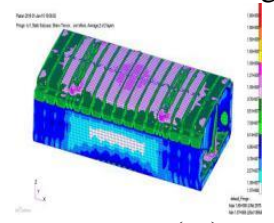

(a) $\mathrm{LC} 1$

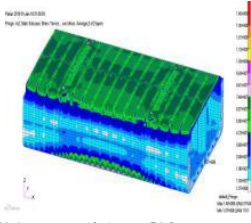

(b)LC2

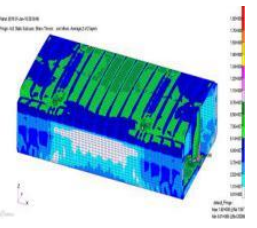

(C)LC1

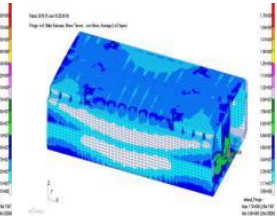

(D)LC2
Fig 4 The cargo compartment is composed of stress In the finite element calculation process, other external forces other than temperature load and boundary conditions remain unchanged are shown in the figure. 

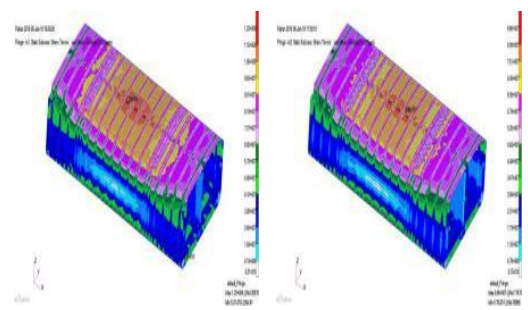

(a) LC1 (b ) LC2

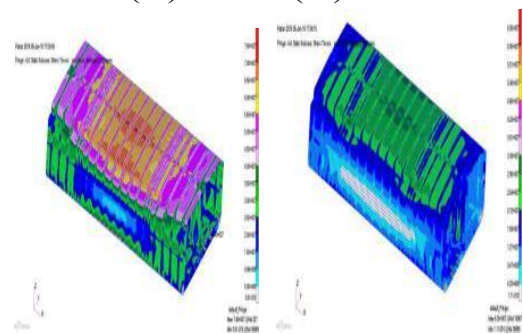

(c) LC3 (d) LC4

Fig 5 The areas and components of the stress concentration in the compartment

It can be seen from the analysis of the synthetic nephogram of the cabin stress in the above mentioned working conditions that the stress in each working condition is lower than the allowable stress but close to it, indicating that the stress of this model tends to the limit. The same condition 1 , condition 3 conditions, load case and bending is the same but at different loading condition but is roughly same, the synthetic stress so loading condition for whole compartment no synthetic stress effects, but because of the synthetic stress is relatively close to the allowable stress, should pay special attention to when building and make the structure of the corresponding improvement measures, working with the working condition of 2 and 4 . However, by referring to working conditions 2 and 3 , it can be seen that under the premise that loading mode has no significant influence on the composite stress of the hull, working conditions and bending are the main factors affecting the composite stress.

The above condition of synthesis of maximum stress component cloud tutu 4 distribution compared with figure 5 stress concentration area in the middle two cargo, this is due to the condition of heat stress, the cargo hold by bending is the main factor of stress concentration, but the stress concentration in the figure 4 is due to the load case of asphalt in cargo hold due to its own temperature, and other external forces under the action of stress, associated with liquid asphalt loading condition. At the same time, according to the figure 5 shows LC1 and LC2 exist thermal stress and thermal stress, about a third of the synthetic stress difference and difference between operating mode 3 and working condition of 4 about two-thirds, condition 3 and conditions due to 4 at the same loading condition, so the difference between those with and without thermal stress is more apparent, combined with table 3 at the same time, the thermal stress is obviously for the synthesis of liquid cargo compartment stress has a great influence, loading temperature field, the working conditions, pod increased peak amplitude value of changeover portion are large, LC3 and LC4 stress peak value increases more than $100 \%$.

Bottom plat result are as follow in firue 6.

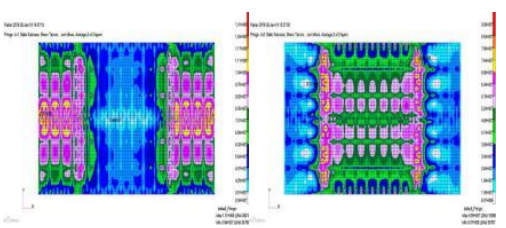

(a) $\mathrm{LC} 1$ (b) LC2

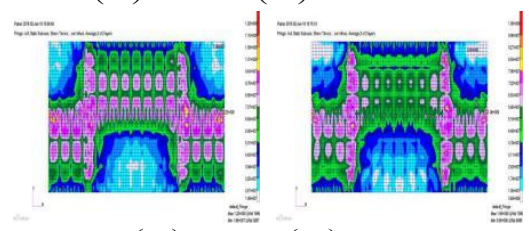

(c) LC3 (d) LC4

Fig 6 Inner bottom composite stress map

In the finite element calculation process, other external forces other than temperature load and boundary conditions remain unchanged are show in the figure. 7

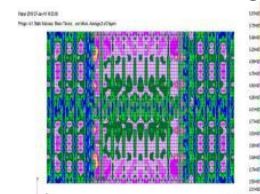

(a) $\mathrm{LC}$

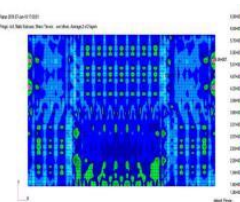

(c) $\mathrm{LC}$

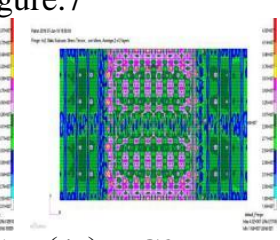

(b) LC2

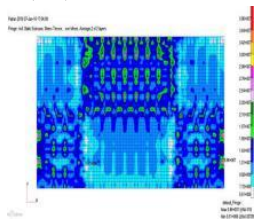

(d) LC4
Fig 7 Stress diagram of bottom plate without thermal stress

Fig 7 Stress diagram of bottom plate without temperature By the inner bottom stress nephogram, the part with the cause of the insulating layer to prevent heat transfer to the floor so compared with figure 7 synthesis stress significantly reduced, so the thermal insulation layer for insulation and prevent heat transfer has a good utility, and the stress distribution and loading of consistent known thermal stress is the internal floor structure by the stress of the main parameters, and loading condition condition 3 and conditions consistent with the 4 different known conditions by stress and bending also has a large influence on the structure stress.

Synthetic stress in the working condition of each cloud tutu 6 and 7, you can see that the floor stress peak value gap between those with and without thermal stress is about $1 / 2$, deduce thermal stress has a great influence for bottom side, so when the finite element calculation does not consider the thermal stress, will appear before and after the calculation of the inside floor of synthetic stress at value gap. Therefore, it can be concluded that for the inner bottom plate, it is subject to the same stress as other components, but other stresses, except thermal stress, only account for less than half of the value of the synthetic stress, and the influence of thermal stress on its synthetic stress accounts for a large part. It can be clearly seen from table 4 that when there is no thermal stress, the peak stress of the inner floor decreases by about half in each working condition. 


\section{CONCLUSION}

This paper takes the analysis of the influence of temperature field on the local strength of the hull of a class 3500t asphalt ship as an example. By comparing the hull stress in the cabin with or without thermal stress field, it can be found that

(1) by establishing the finite element model and defining the correct material parameters and temperature conditions, the finite element software can accurately simulate the temperature field distribution of asphalt ship under the action of asphalt, so as to calculate the temperature stress.

(2) for the asphalt ship, the temperature of the liquid cargo asphalt itself is the main factor leading to greater stress, and high-temperature cargo significantly increases the longitudinal stress of the hull plate. At the same time, when there is no thermal stress in the loading load, the liquid and cargo stress is mainly concentrated in the center of the cargo compartment, which is caused by the bending of the hull. This has guiding significance for the construction of asphalt ship.

\section{REFERENCE}

[1] Xiaoqing Teng, Yong Gu.type double hull hull structure steady temperature field and temperature stress of China shipbuilding [J]. China shipbuilding. 2000.41 (2) : 53-65

[2] Xiao Zhang,Analysis of temperature field and thermal stress of asphalt tanker [D]. Huazhong university of science and technology.2016

[3] Bozhen Chen, Yuren Hu. Calculation of temperature distribution and thermal stress of ship hull $[\mathrm{J}]$. Journal of Shanghai jiaotong university.1995.29(3).

[4] Liu yujun. Research on thermal elastoplastic mechanism and simulation method of water-fire bending plate [D]. Dalian university of technology.2017.7

[5] Honggang Wang. introduction to elastic mechanics [M]. Tsinghua university press. 1988

[6] Zhilun Xu. elastic mechanics (second edition)[M]. Higher education press.2004

[7] Yongli wang. Finite element calculation of ship structural strength [D]. Wuhan university of technology.2016 